\title{
Valor nutritivo e estudo cinético do trato digestivo de dietas contendo grãos secos ou ensilados de sorgo de baixo e alto tanino para eqüinos ${ }^{1}$
}

\author{
Kátia de Oliveira ${ }^{2}$, Ciniro Costa ${ }^{3}$, Marília Gabriela Faustino ${ }^{4}$, Vanessa da Silva Gasque ${ }^{4}$, \\ Vanessa Pillon dos Santos ${ }^{4}$, Marina Noronha Lima ${ }^{4}$, Virgilio Franco do Nascimento Filho ${ }^{5}$, \\ Adibe Luiz Abdalla 6
}

\author{
1 Parte do trabalho de tese de Doutorado da primeira autora, financiado com recursos da Fundação para o Desenvolvimento da UNESP - \\ FUNDUNESP. \\ 2 Pós-Doutoranda - Departamento de Melhoramento e Nutrição Animal - FMVZ/UNESP, Campus de Botucatu, CEP: $18603-970$ - SP. \\ 3 Departamento de Melhoramento e Nutrição Animal - FMVZ/UNESP, Campus de Botucatu, CEP: 18 603-970, Botucatu - SP. \\ 4 Acadêmica da Faculdade de Ciências Agrárias da Universidade de Marília. \\ ${ }^{5}$ LIN/CENA - USP, CEP: 13400-970, Piracicaba - SP. \\ ${ }^{6}$ LANA/CENA - USP, CEP: 13400-970, Piracicaba - SP.
}

RESUMO - Quatro éguas sem raça definida (idade e peso corporal médios de seis anos e $400 \mathrm{~kg}$ ) foram distribuídas em delineamento experimental em quadrado latino para se avaliar o valor nutritivo e o estudo cinético do trato digestivo de grãos secos ou ensilados de sorgo de baixo e alto conteúdos de tanino na alimentação de eqüinos. Os tratamentos consistiram de dietas contendo dois híbridos de grãos de sorgo (baixo e alto níveis de tanino) e dois métodos de conservação (secos e ensilados). As dietas foram isoprotéicas (12,4\% PB), com ingestão diária de MS estabelecida em 1,5\% PV (relação feno:concentrado de 50: 50). Os parâmetros de trânsito gastrintestinal avaliados foram: k1 (taxa de passagem pelo intestino grosso), k2 (taxa de passagem pelo estômago), TT (tempo de trânsito), TMR (tempo médio de retenção) e TMRT (tempo médio de retenção total). Os tratamentos não afetaram os coeficientes de digestibilidade aparente (CDa) da MS e do amido, cujos valores médios foram 54,04 e 98,91\%, respectivamente. Verificou-se efeito benéfico da ensilagem dos grãos de sorgo de alto conteúdo de tanino sobre a digestibilidade da PB e FDN. A CDa da PB e FDN para a dieta contendo grãos secos de sorgo de alto teor de tanino foi de 49,76 e 32,20\% e para as dietas com grãos de sorgo de baixo conteúdo de tanino (seco ou ensilado) e grãos ensilados de sorgo de alto teor de tanino foi de 65,63 e 43,32\%, respectivamente. Obteve-se somente efeito do método de conservação dos grãos de sorgo ( secos vs ensilados) sobre o TMR, em que o valor para as dietas com silagens de grãos ensilados e secos foi, respectivamente, de 40,08 e 37,9h. Concluiu-se que os grãos de sorgo secos de alto teor de tanino não devem ser usados como principal grão energético nos concentrados para eqüinos, por diminuírem a digestibilidade da proteína e fibra.

Palavras-chave: cavalo, digestibilidade, taxa de passagem, trânsito gastrintestinal

\section{Nutritive value and kinetics study of digestive tract of diets to equine containing dry grains or high-moisture of sorghum grains silage of low and high tannin}

\footnotetext{
ABSTRACT - Four crosbred mares averaging six years and $400 \mathrm{~kg} \mathrm{BW}$ were allotted to latin square design. The objective was to evaluate the nutritive values and kinetics of digestive tract of dry grains or high-moisture grains silage of sorghum with low and high tannin in the feeding of equines. The treatments consisted of diets containing two hybrids of sorghum grains (low and high tannin) and to methods of conservation (dry an ensiled). Diets were formulated to be isoprotein (12.4\% $\mathrm{CP}$ ) with daily DM intake established in $1.5 \% \mathrm{BW}$ (hay to concentrate ratio of 50:50). The parameters of gastrointestinal transit were: $\mathrm{k} 1$ (passage rate in the large intestine); k2 (passage rate in the stomach); TT (transit time); MRT (mean retention time) and TMRT (mean total retention time). No effect treatment was observed for aCD of DM and starch, whose means values were 54.04 and $98.91 \%$, respectively. A benefic effect of the ensiling of high tannin and high-moisture sorghum grains on digestibility of CP and NDF. The aCD of CP and NDF for diets containing high tannin and dry grains of sorghum was of $49.76 \%$ and $32.20 \%$ and for diets containing of low tannin sorghum grains (dry and ensiled) and high tannin and high-moisture sorghum grains was of 65.63 and $43.32 \%$, respectively. There was effect only of the conservation method of the sorghum grains (dry versus ensiled) on the TMR, where the value for the diets with silages of high-moisture grains and dry grains was, respectively, of 40.08 and $37.9 \mathrm{~h}$. In conclusion, high tannin sorghum dry grains should not be used as the main grain in energetic concentrates for horses, because they reduced the digestion of protein and fiber.
}

Key Words: digestibility, gastrintestinal transit, horse, passage rate 


\section{Introdução}

No Brasil, o principal grão energético utilizado nas rações é o milho, mas o cultivo de alimentos alternativos cresceu de maneira acentuada a partir de 1998 (Sologuren, 2000).

Segundo Lewis (2000), o grão de sorgo de baixo teor de tanino constitui um cereal nutritivo para os eqüinos e pode ser oferecido como único grão na ração desta espécie, sem nenhum efeito prejudicial. Corroborando esta recomendação, pesquisas têm notificado semelhança nos coeficientes de digestibilidade (CD) da MS e dos principais nutrientes entre o milho e o sorgo na espécie eqüina (Gibbs et al., 1996; Whitaker \& Carvalho, 1997). Gobesso (2001), avaliando a digestão pré-cecal e total de diversos grãos de cereais na alimentação de cavalos fistulados no íleo, observou efeito significativo apenas para o $\mathrm{CD}$ da $\mathrm{PB}$ no trato digestivo total, que apresentou maiores valores para a dieta com milho e grãos de sorgo, respectivamente, de 77,0 e 70,3\%.

Considerando-se os grãos de sorgo colhidos logo após a maturação fisiológica, com $30 \%$ de umidade (U), a sua composição química é similar à do sorgo normalmente colhido com $18 \%$ U. Crenshaw et al. (1984) observaram para grãos colhidos com 14 e 25\% U valores de PB de 10,5 e 10,3\% $\mathrm{PB}$, respectivamente, enquanto Myer et al. (1986), trabalhando com grãos de sorgo contendo 11 e $25 \%$ U, observaram tendência de os grãos de sorgo de alto conteúdo de tanino terem maiores conteúdos de proteína, lisina, metionina e EE que o sorgo de baixo teor de tanino.

Adicionalmente, a estocagem de grãos úmidos de sorgo em ambiente anaeróbio tem demonstrado efeito benéfico sobre a desativação dos taninos. Cogita-se que o mecanismo de desativação dos taninos pela água contida nos grãos ensilados (colhidos úmidos ou reconstituídos) seja semelhante à reação ocorrida nos grãos colhidos no estádio próximo à maturação fisiológica. Assim, a ensilagem dos grãos de sorgo de alto nível de tanino com $25 \%$ U tem resultado em decréscimo de $95 \%$ nos teores de taninos, assemelhando-se ao sorgo de baixo conteúdo de tanino (Mitaru et al., 1983).

O estudo do trânsito gastrintestinal da digesta nos diferentes compartimentos do trato digestivo é importante na avaliação nutricional dos alimentos, pois permite mensurar o local e a extensão da digestão dos nutrientes da dieta. $\mathrm{O}$ uso de modelos comportamentais e de marcadores da digesta tem sido extensivamente utilizado em ruminantes, com metodologias bem estabelecidas, porém, esta não é a realidade na experimentação com eqüinos. As primeiras publicações sobre o assunto objetivaram a mensuração do tempode passagem de partículas marcadas pelo trato digestivo de cavalos, cujos resultados foram divergentes. Hintz \& Loy (1966) relataram que o tempo de passagem do óxido crômico foi de 63 horas após alimentação, enquanto Haenlein et al. (1966) e Vander Noot et al. (1967) verificaram tempos de 48 e 96 horas, respectivamente. Recentemente, Oliveira et al. (2001) avaliaram a cinética de passagem da digesta em eqüinos alimentados com dietas compostas de feno de coastcross e concentrado nas proporções de 100:0, 80:20, 60:40 e 40:60. Esses autores observaram que o tempo de retenção da digesta variou de 40,58 a 47,95 horas, independentemente da dieta.

O uso de grãos ensilados de sorgo no Brasil é escasso, inexistindo pesquisas que viabilizem este alimento para eqüinos nas literaturas nacional e internacional. Entretanto, Santos et al. (2002) não observaram efeitos negativos de grãos ensilados de milho (SGUM) sobre a ingestão e aceitabilidade pelos eqüinos. Neste sentido, objetivou-se com esta pesquisa avaliar a utilização de dietas com silagens de grãos de sorgo de baixo e alto teores de tanino, em comparação aos grãos secos, na alimentação de eqüinos por meio de ensaio de digestibilidade e da avaliação do trânsito da digesta no trato gastrintestinal.

\section{Material e Métodos}

O experimento foi conduzido no Setor de Eqüinocultura da Universidade de Marília, Marília, SP. Quatro éguas sem raça definida (idade e peso corporal [PC] médios de seis anos e $400 \mathrm{~kg}$ ) foram distribuídas em delineamento experimental quadrado latino $(4 \times 4)$, designado por Cochran \& Cox (1967). Os tratamentos consistiram de concentrado (grãos de sorgo como a principal fonte de energia) e as fontes de variação foram o tipo de grão de sorgo (baixo e alto teores de tanino) e dois processos de conservação (seco ensilado). As dietas, cujas composições química, centesimal e química encontram-se nas Tabelas 1,2 e 3, respectivamente, foram formuladas para serem isoprotéicas, constituindo os seguintes tratamentos: dieta com concentrado contendo grãos secos de sorgo de baixo teor de tanino, dieta com concentrado contendo grãos secos de sorgo de alto conteúdo de tanino, dieta com concentrado contendo grãos úmidos de sorgo de baixo teor de tanino e dieta com concentrado contendo grãos úmidos de sorgo de alto conteúdo de tanino.

Os grãos úmidos de sorgo foram colhidos com 33 e $39 \%$ de U, para os grãos de alto e baixo níveis de tanino, respectivamente. Em seguida, os grãos foram moídos em peneira com crivo de $6 \mathrm{~mm}$ e compactados em tambores 
experimentais de $100 \mathrm{~L}$. Os silos permaneceram fechados por quatro meses e, após abertura das silagens, foram colhidas amostras do material, que permaneceram em freezer a $-10^{\circ} \mathrm{C}$, para análises bromatológicas. A colheita dos grãos secos de sorgo (14,1 e 15,5\% U para os grãos de baixo e alto teores de tanino, respectivamente) foi realizada um mês após a dos grãos úmidos. Em seguida, os grãos foram ensacados e expurgados para evitar ataque de insetos e, após secagem ao sol, coletadas amostras para posteriores análises.

A quantificação dos taninos presentes nos grãos secos e nas silagens de grãos úmidos de sorgo foi realizad a no LANA/CENA/USP, com base na metodologia descrita por Makkar et al. (1988) e Makkar (2001). Estas amostras foram moídas a $0,25 \mathrm{~mm}$, submetidas à présecagem em estufa a $40^{\circ} \mathrm{C}$; com uma alíquota de $200 \mathrm{mg}$ procedeu-se à extração das frações solúveis. Após, aos tubos de ensaio de $15 \mathrm{~mL}$ foram adicionados $10 \mathrm{~mL}$ do solvente (metanol a 70\%), mantidos em banho frio (gelo + água) e avaliados por ultra-som durante 4 minutos (repetido por três vezes), até um total de 12 minutos. O conteúdo foi centrifugado a $4^{\circ} \mathrm{C}$ por 20 minutos, aproximadamente a $1.900 \mathrm{rpm}$. O sobrenadante foi coletado e conservado no gelo. Tomou-se $0,5 \mathrm{~mL}$ do sobrenadante em tubos de ensaio, aos quais, em seguida, foi adicionada água destilada para completar $1 \mathrm{~mL}$. O extrato diluído foi adicionado de 0,5 mL do reagente de Folin Ciocalteau $1 \mathrm{~N}$ e 2,50 mL da solução de carbonato de sódio ( $20 \mathrm{~g}$ de carbonato de sódio dissolvidos em $150 \mathrm{~mL}$ de água destilada, completando-se o volume para $200 \mathrm{~mL}$ ). Os tubos foram agitados e mantidos em repouso por 40 minutos. A leitura foi efetuada em espectofotrômetro a $725 \mathrm{~nm}$ e o teor de taninos totais, em curva padrão de ácido tânico.

A quantidade de alimento fornecida aos animais foi estabelecida segundo as recomendações do NRC (1989), para eqüinos, visando atender às exigências desta catego- ria. Portanto, a ingestão de MS total foi de $1,5 \%$ do PC, composta por $50 \%$ de concentrado e $50 \%$ de feno de coastcross picado em triturador de faca. As dietas foram fornecidas em três refeições (8h30, 13h30 e 16h30), sendo a última composta apenas por feno de coastcross. As sobras foram retiradas e pesadas 15 minutos antes do fornecimento, para se obter a quantidade de nutrientes ingeridos.

O experimento teve duração total de 48 dias, subdivididos em quatro períodos de 12 dias cada. Os primeiros seis dias corresponderam à fase de adaptação dos animais às instalações, dietas e condições de manejo, de acordo com as metodologias descritas por Gibbs et al. (1996) e Oliveira et al. (2003), para os ensaios de digestibilidade, e Holland et al. (1998), para avaliação da cinética digestiva. A fase seguinte foi destinada à coleta parcial de fezes, com duração de seis dias, na qual se determinaram os coeficientes de digestibilidade e as estimativas do trânsito gastrintestinal das dietas experimentais. Durante todo período experimental, os animais ficaram alojados em baias de alvenaria ( $4 \times 4 \mathrm{~m}$ ), com piso de terra batida, comedouros para concentrado e feno e bebedouro para consumo de água ad libitum. Antes do início do experimento, foi administrado vermífugo de amplo espectro às éguas, que foram soltas em redondel no final de cada período.

Os coeficientes de digestibilidade aparente (CDa) de MS, amido, PB e FDN foram determinados por método indireto, utilizando-se, como indicador interno, a cinza insolúvel em ácido clorídrico a 2N (CIA) (Van Keulen \& Young, 1977). As fezes foram coletadas diretamente do reto do animal, duas vezes ao dia, inicialmente às 8 e 14h, no segundo dia às $9 \mathrm{~h}$ e $15 \mathrm{~h}$ e, assim, sucessivamente, até o último dia com coletas às 13 e 19h, com a finalidade de reduzir o efeito de variação diurna (Haenlein et al., 1966). Para estimativa da produção fecal, foram realizadas análises de CIA nos alimentos (concentrado e volumoso) e nas

Tabela 1 - Composição química dos alimentos ${ }^{1}$

Table 1 - Chemical composition of feeds

\begin{tabular}{|c|c|c|c|c|c|c|}
\hline \multirow[t]{2}{*}{$\begin{array}{l}\text { Alimento } \\
\text { Feed }\end{array}$} & \multirow[t]{2}{*}{$\begin{array}{c}\mathrm{MS}(\%) \\
D M\end{array}$} & \multicolumn{4}{|c|}{$\begin{array}{c}\text { Nutriente (\% MS) } \\
\text { Nutrient (DM \%) }\end{array}$} & \multirow[t]{2}{*}{$\mathrm{T} \mathrm{T}^{2}$} \\
\hline & & $\begin{array}{l}\mathrm{PB} \\
C P\end{array}$ & $\begin{array}{l}\mathrm{EE} \\
E E\end{array}$ & $\begin{array}{l}\text { FB } \\
C F\end{array}$ & $\begin{array}{l}\text { FDN } \\
N D F\end{array}$ & \\
\hline Sorgo seco $(\mathrm{BT})^{3}$ (Dry sorghum, LT) & 85,92 & 10,40 & 4,27 & 2,76 & 42,10 & 0,60 \\
\hline Sorgo seco $(\mathrm{AT})^{4}$ (Dry sorghum, $\left.H T\right)$ & 84,51 & 9,00 & 2,19 & 1,98 & 36,41 & 1,41 \\
\hline Sorgo ensilado (BT) (Ensiled sorghum, $L T$ ) & 61,27 & 11,18 & 4,19 & 3,40 & 22,41 & 0,55 \\
\hline Sorgo ensilado (AT) (Ensiled sorghum, $H T$ ) & 67,84 & 10,00 & 2,75 & 2,42 & 19,27 & 0,44 \\
\hline Farelo de soja (Soybean meal) & 89,23 & 49,67 & 2,40 & 6,71 & $\mathrm{nd}^{5}$ & nd \\
\hline Farelo de trigo (Wheat bran) & 89,76 & 17,10 & 2,10 & 10,39 & nd & nd \\
\hline Feno de coastcross (Coastcross hay) & 91,10 & 5,21 & nd & 41,73 & 84,63 & nd \\
\hline
\end{tabular}

${ }^{1}$ Dados obtidos no Laboratório de Nutrição Animal, do Centro de Energia Nuclear na Agricultura (CENA) USP; ${ }^{2}$ TT - taninos totais. Valores expressos em $100 \%$ de MS, como equivalentes de ácido tânico; ${ }^{3} \mathrm{BT}=$ baixo tanino; ${ }^{4} \mathrm{AT}=$ alto tanino; ${ }^{5}$ nd $=$ não determinado.

${ }^{1}$ Calculated composition based on analyses in Animal Nutrition in Centro de Energia Nuclear na Agricultura (CENA) USP; ${ }^{2}$ TT= total tanin. Values expressed in $100 \%$ DM, as equivalent to tannin acid; ${ }^{3} L T=$ low tannin; ${ }^{4} H T=$ high tannin; ${ }^{5}$ nd $=$ not determined. 
Tabela 2 - Composições química dos alimentos e centesimal e química dos concentrados experimentais $(\% \mathrm{MS})^{1}$

Table 2 - Chemical feed composition and percentage and chemical compositions of the experimental concentrates (\%DM)

Alimento (\%)

Feed

Sorgo em grão (Sorghum grain)

Farelo de soja (Soybean meal)

Farelo de trigo (Wheat bran)

Feno de coastcross (Coastcross hay)

Sal + Mistura $^{1}$ (Salt + Mixture $)$

$(\%)$

1 Composição da mistura mineral e vitamínica (Composition of mix and vitamin mix):Ca, $185 \mathrm{~g} ; \mathrm{P}, 180 \mathrm{~g} ; \mathrm{Mg}, 25 \mathrm{~g} ; \mathrm{Zn}, 5000 \mathrm{mg} ; \mathrm{Cu}, 1.300 \mathrm{mg}$; Co, $350 \mathrm{mg} ; \mathrm{Mn}$, $2.500 \mathrm{mg} ; \mathrm{Fe}, 3.000 \mathrm{mg}$; I, $300 \mathrm{mg}$; Se, $20 \mathrm{mg} ; \mathrm{F}, 1.800 \mathrm{mg}$; Vit. A, $50.000 \mathrm{UI}$

Tabela 3 - Composição química dos concentrados experimentais ${ }^{1}$

Table 3 - Chemical composition of the experimental concentrates

\begin{tabular}{lcccc}
\hline $\begin{array}{l}\text { Nutriente } \\
\text { Nutrient }\end{array}$ & $\begin{array}{c}\text { SSBT } \\
D S L T\end{array}$ & $\begin{array}{c}\text { SSAT } \\
D S H T\end{array}$ & $\begin{array}{r}\text { SEBT } \\
E S L T\end{array}$ & $\begin{array}{r}\text { SEAT } \\
E S H T\end{array}$ \\
\hline MS $(\%)^{2}$ & 86,68 & 87,83 & 69,21 & 72,68 \\
$D M$ & 12,77 & 12,11 & 12,40 & 12,17 \\
PB $(\%)^{2,4}$ & 40,87 & 38,60 & 32,48 & 26,47 \\
$C P$ & $58, \%)^{2,4}$ & 58,25 & 55,48 & 53,24 \\
FDN $\left(\begin{array}{l}\text { NDF } \\
\text { Amido }(\%)^{3,4}\end{array}\right.$ & 59,22 & & & \\
Starch & & &
\end{tabular}

${ }^{1}$ SSBT = sorgo seco de baixo teor de tanino, SSAT = sorgo seco de alto teor de tanino, SEBT = sorgo ensilado de baixo teor de tanino SEAT = sorgo ensilado de alto teor de tanino.

2 Dados obtidos no laboratório de Nutrição Animal, do Centro de Energia Nuclear na Agricultura (CENA) USP.

${ }^{3}$ Dados obtidos no Laboratório de Bromatologia, do Departamento de

Zootecnia, ESALQ/USP

4 Nutrientes em \%MS.

${ }^{1} D S L T=$ dry sorghum of low tannin, $D S H T=$ dry sorghum of high tannin, ESLT = ensiled sorghum of low tannin and ESHT = ensiled sorghum of high tannin.

2 Calculated composition based on analyses in Animal Nutrition in Centro de Energia Nuclear na Agricultura (CENA) USP.

${ }^{3}$ Calculated composition based on analyses in Chemical Laboratory, Department of Animal Science, ESALQ/USP.

${ }^{4}$ Nutrient in \%DM.

fezes. Assim, a quantidade de MS fecal estimada foi obtida dividindo-se a quantidade consumida de CIA (g) pela porcentagem de CIA nas fezes e multiplicando-se o resultado por 100 (Araújo, 1999). As análises bromatológicas dos alimentos e das fezes foram feitas segundo a metodologia descrita em Silva (1989) e do amido, de acordo com Macrae \& Armstrong (1968). Os cálculos dos CDaMS e dos nutrientes $(\mathrm{CDaN})$ avaliados foram obtidos por meio das seguintes fórmulas:

\begin{tabular}{|c|c|c|c|}
\hline \multirow[t]{2}{*}{ CDaMS $=100-100 x$} & \multicolumn{2}{|c|}{$\%$ CIA na dieta } & \\
\hline & \multicolumn{2}{|c|}{$\%$ CIA nas fezes } & \\
\hline \multirow[t]{2}{*}{$\mathrm{CDaN}=100-100 \mathrm{x}$} & $\begin{array}{c}\text { \% CIA na MS } \\
\text { da dieta }\end{array}$ & $\mathrm{x}$ & $\begin{array}{l}\% \text { nutriente } \\
\text { nas fezes }\end{array}$ \\
\hline & $\begin{array}{r}\% \text { CIA na MS } \\
\text { das fezes }\end{array}$ & & $\begin{array}{l}\% \text { nutriente } \\
\text { no alimento }\end{array}$ \\
\hline
\end{tabular}

O monitoramento do trânsito gastrintestinal foi realizado com base no modelo proposto por Grovum \& Williams (1973), adaptando-o para o estudo com eqüinos, em que se avaliaram os seguintes parâmetros: $k 1$ - taxa de passagem da fração lenta da digesta, correspondendo ao intestino grosso; $k 2$ - taxa de passagem da fração rápida da digesta, referente ao estômago; TT - tempo de trânsito necessário para que a primeira partícula marcada aparecesse nas fezes, correspondendo ao compartimento tubular, ou seja, intestino delgado; TMR - tempo médio de retenção do marcador pelos compartimentos com capacidade de mistura, estômago $\left(\mathrm{TMR}_{2}\right)$ e intestino grosso $\left(\mathrm{TMR}_{1}\right)$; e TMRT - tempo médio de retenção total do marcador, incluindo todo trato digestivo. Foi usado como marcador o cromo mordentado à fibra do feno de coastcross (Cr-FDN), para marcar a fase sólida da digesta, segundo procedimento desenvolvido por Uden et al. (1980).

A administração do marcador foi realizada no primeiro dia do período de coleta de fezes, quando foram fornecidos, em dose única, $30 \mathrm{~g}$ de Cr-FDN (partículas de $1 \mathrm{~mm}$ ), juntamente com o concentrado no período da manhã. Neste procedimento, as sobras de alimento foram recolhidas no último dia de adaptação (18 h), procedendo-se, no dia seguinte, à administração de Cr-FDN e um palatabilizante (açúcar), oferecidos em um balde, para evitar a perda do marcador durante o consumo pelas éguas. As coletas de fezes (aproximadamente $200 \mathrm{~g} / \mathrm{animal}$ ) para determinação do marcador através do trato gastrintestinal foram realizadas nos tempos de $0,4,8,12,16,20,24,30,36,42,48,54,60$, 66, 72 e 78 horas pós-dosagem, segundo a metodologia descrita por Cuddeford et al. (1992). Os parâmetros de trânsito gastrintestinal foram calculados, segundo Grovum \& Williams (1973), por meio das seguintes equações:

$$
\mathrm{TT}=\frac{\ln \mathrm{A}_{2}-\ln \mathrm{A}_{1} ;}{k_{2}-k_{1}} \quad \mathrm{TMR}_{1}=\frac{1 ;}{k_{1}} \quad \mathrm{TMR}_{2}=\frac{1 ;}{k_{2}}
$$

$\mathrm{TMR}=\mathrm{TMR}_{1}+\mathrm{TMR}_{2}$ e $\mathrm{TMRT}=\mathrm{TT}+\mathrm{TMR}_{1}+\mathrm{TMR}_{2}$.

em que $\ln \mathrm{A}_{1}$ e $\ln \mathrm{A}_{2}$ são constantes do modelo sem valor biológico definido pelo comportamento de excreção do marcador, obtidas por meio das equações de suas curvas lineares, ramos descendente e crescente, respectivamente.

Utilizou-se a metodologia proposta por Blaxter et al. (1956) para se estimar somente o tempo médio de retenção (TMR), com o objetivo de melhor comparar os resultados obtidos em outros ensaios com a espécie eqüina, por apresentar-se como principal modelo utilizado. OTMR foi calculado de acordo com a equação: 


$$
\mathrm{TMR}=\frac{\sum \mathrm{m}_{\mathrm{i}} \mathrm{t}_{\mathrm{i}}}{\sum \mathrm{m}_{\mathrm{i}}}
$$

em que $\mathrm{m}_{\mathrm{i}}$ é a quantidade de marcador excretado ao tempo $\mathrm{t}_{\mathrm{i}}$ após administração do mesmo. A recuperação do marcador foi determinada multiplicando-se a concentração do marcador nas fezes pela produção de fezes, estimada por meio da CIA, e dividindo-se o resultado pela quantidade de marcador ingerido (Krysl et al., 1988).

A análise do $\mathrm{Cr}$ nas fezes e no material original foi realizada por meio da técnica analítica nuclear de fluorescência de raios X, por dispersão de energia (ED-XRF), em equipamento disponível no Laboratório de Instrumentação Nuclear, da Divisão de Desenvolvimento de Métodos e Técnicas Analíticas e Nucleares, do CENA/USP (Nascimento Filho, 1999).

Os dados referentes aos coeficientes de digestibilidade e do trânsito da digesta no trato gastrintestinal foram analisados por meio da análise de variância doStatistical Analysis $S$ ystem (SAS, 2000), em que as fontes de variação incluídas no modelo foram tratamento, período e animal. Os contrastes ortogonais avaliados foram o tipo de grão de sorgo (baixo ou alto teor de tanino), o método de conservação (seco ou ensilado) e a interação tipo de grão $x$ método de conservação. Quando a interação não foi significativa, utilizou-se a probabilidade dos efeitos principais. A comparação entre médias foi realizada pelo teste Tukey, a 5\% de significância.

\section{Resultados e Discussão}

Apesar de a ensilagem não ser comumente ingerida por cavalos, não foram observadas diferenças $(\mathrm{P}>0,05)$ no consumo das dietas contendo grãos de sorgo com baixo e alto conteúdos de tanino em ambas as formas de conservação (Tabela 4). Além disso, a característica adstringente da ração contendo grãos de sorgo de alto teor de tanino não interferiu no consumo. Similarmente, Santos et al. (2002) não verificaram alterações no consumo de dieta constituída pela inclusão de $30 \%$ de SGUM em potros de um ano de idade.

O método de conservação ( seco ou ensilado) e o tipo de grãos de sorgo (baixo ou alto teores de tanino) não afetaram $(\mathrm{P}>0,05)$ o coeficiente de digestibilidade da MS (CDMS) e do amido das dietas em eqüinos, cujo valor médio obtido foi de 54,04 e 98,91\%, respectivamente (Tabela 5). Estes valores podem ser considerados intermediários em relação aos trabalhos realizados com cavalos, em que se utilizaram grãos secos de sorgo em substituição ao milho.
Assim, Saint Just (1989), em ensaio com éguas gestantes recebendo dieta constituída por $34,5 \%$ de sorgo no concentrado em substituição total ao milho, verificou 53,2\% de CDMS, enquanto Whitaker \& Carvalho (1997), utilizando-se concentrado com $30 \%$ de sorgo, e Gobesso (2001), incluindo $48,5 \%$ do mesmo para cavalos, observaram CDMS de 68,63 e 66,5\%, respectivamente. A média do CDMS obtido neste ensaio foi um pouco inferior ao esperado para eqüinos, provavelmente em razão da má qualidade do feno de coastcross utilizado, com $84,63 \%$ de FDN, sendo necessário fornecê-lo picado para garantir adequados consumo e motilidade intestinal às éguas.

Pioneiramente, Santos et al. (2002), determinando o valor nutritivo da SGUM em potros, observaram melhora $(\mathrm{P}<0,05)$ no CDMS para a dieta-teste $(30 \%$ de SGUM) em comparação à ração contendo grãos de milho, de 73,32 e $68,91 \%$, respectivamente. Este fato não foi observado entre os grãos secos e ensilados de sorgo na alimentação de éguas neste estudo. Entretanto, corroboraram os resultados obtidos por Crenshaw et al. (1984), que avaliaram em suínos a utilização de grãos secos ou ensilados de sorgo, não detectando diferenças significativas $(\mathrm{P}>0,05)$ para $\mathrm{o}$ CDMS entre as fontes testadas. Contudo, em relação ao efeito da interação tipo do grão de sorgo (alto ou baixo teores de tanino) $\times$ método de conservação (seco ou ensilado) na experimentação com suínos, houve melhora $(\mathrm{P}<0,05)$ no CDMS quando os grãos de sorgo de alto conteúdo de tanino, em relação aos de baixo teor de tanino, foram ensilados.

Os valores de digestibilidade da PB para as dietas contendo grãos de sorgo de baixo teor de tanino (seco ou ensilado) e grãos ensilados de alto conteúdo de tanino foram superiores aos da dieta com grãos secos de sorgo de alto nível de tanino, demonstrando o efeito benéfico da ensilagem da variedade de sorgo de alto teor de tanino sobre a desativação dos taninos, na alimentação de equiinos, evitando que se liguem à proteína da dieta. Este fato era esperado, pois já existem resultados semelhantes publicados para aves (Mitaru et al., 1983; Grigoletto et al., 2003), suínos (Cousins et al., 1981; Myer et al., 1986; Patricio et al., 2003) e ruminantes (Hibberd et al. 1985; Streeter et al., 1990).

Quanto ao método de conservação, não foram observadas diferenças significativas entre os processos sobre o CDPB das dietas com grãos de sorgo de baixo teor de tanino, denotando que a ensilagem não influenciou $(\mathrm{P}>0,05)$ positivamente esta variável. Da mesma forma, Santos et al. (2002), em eqüinos, não verificaram efeito positivo do uso de grãos ensilados de milho em relação aos grãos secos de milho sobre este parâmetro. Contudo, têm-se verificado 
Tabela 4 - Ingestão de MS (IMS) do concentrado e da dieta contendo grãos de sorgo com baixo e alto teores de tanino, sob dois métodos de conservação, fornecida aos eqüinos

Table 4 - DM intake (DMI) of concentrate and of the diet containing sorghum grains with low and high tannin submitted to two methods of conservation, fed to equines

\begin{tabular}{|c|c|c|c|c|c|c|}
\hline \multirow[t]{3}{*}{$\begin{array}{l}\text { IMS (kg/dia) } \\
D M I(k g / \text { day })\end{array}$} & \multicolumn{4}{|c|}{$\begin{array}{l}\text { Dieta contendo grãos de sorgo } \\
\text { Diet containing sorghum grain }\end{array}$} & \multirow[t]{3}{*}{$\begin{array}{c}\text { Média }^{1} \\
\text { Mean }\end{array}$} & \multirow[t]{3}{*}{$\mathrm{CV}(\%)$} \\
\hline & \multicolumn{2}{|c|}{$\begin{array}{l}\text { Baixo tanino } \\
\text { Low tannin }\end{array}$} & \multicolumn{2}{|c|}{$\begin{array}{l}\text { Alto tanino } \\
\text { High tannin }\end{array}$} & & \\
\hline & $\begin{array}{l}\text { Seco } \\
\text { Dry }\end{array}$ & $\begin{array}{c}\text { Ensilado } \\
\text { Ensiled }\end{array}$ & $\begin{array}{l}\text { Seco } \\
\text { Dry }\end{array}$ & $\begin{array}{c}\text { Ensilado } \\
\text { Ensiled }\end{array}$ & & \\
\hline $\begin{array}{l}\text { Concentrado } \\
\text { Concentrate }\end{array}$ & 3,08 & 2,77 & 3,06 & 2,37 & 2,82 & 18,44 \\
\hline $\begin{array}{l}\text { Dieta } \\
\text { Diet }\end{array}$ & 6,11 & 5,78 & 6,01 & 5,43 & 5,83 & 8,90 \\
\hline
\end{tabular}

${ }^{1}$ Médias não diferem $(\mathrm{P}>0,05)$ pelo teste Tukey.

${ }^{1}$ Means did not differ $(P>0.05)$ by Tukey test.

Tabela 5 - Digestibilidade aparente da MS e dos nutrientes em eqüinos alimentados com dietas contendo grãos de sorgo de baixo e alto teor de tanino sob dois métodos de conservação (\% MS)

Table 5 - Apparent digestibility of DM and of nutrients in equine fed diets containing sorghum grains with low and high tannin submitted to two methods of conservation $(\% D M)$

\begin{tabular}{|c|c|c|c|c|c|c|c|}
\hline \multirow[t]{3}{*}{$\begin{array}{l}\text { Digestibilidade aparente (\%) } \\
\text { Apparent digestibility }\end{array}$} & \multicolumn{4}{|c|}{$\begin{array}{l}\text { Dieta contendo grãos de sorgo } \\
\text { Diet containing sorghum grain }\end{array}$} & \multicolumn{2}{|c|}{$\begin{array}{l}\text { Efeito principal }{ }^{1} \\
\quad \text { Main effect }\end{array}$} & \multirow[t]{3}{*}{$\mathrm{CV}(\%)$} \\
\hline & \multicolumn{2}{|c|}{$\begin{array}{l}\text { Baixo tanino } \\
\text { Low tannin }\end{array}$} & \multicolumn{2}{|c|}{$\begin{array}{l}\text { Alto tanino } \\
\text { High tannin }\end{array}$} & \multirow[t]{2}{*}{ I } & \multirow[t]{2}{*}{ II } & \\
\hline & $\begin{array}{l}\text { Seco } \\
\text { Dry }\end{array}$ & $\begin{array}{l}\text { Ensilado } \\
\text { Ensiled }\end{array}$ & $\begin{array}{l}\text { Seco } \\
\text { Dry }\end{array}$ & $\begin{array}{c}\text { Ensilado } \\
\text { Ensiled }\end{array}$ & & & \\
\hline $\operatorname{MS}(D M)$ & $55,08 \mathrm{a}$ & $56,68 \mathrm{a}$ & $49,76 a$ & $54,62 \mathrm{a}$ & $\mathrm{ns}$ & $\mathrm{ns}$ & 6,71 \\
\hline $\mathrm{PB}(C P)$ & $65,23 \mathrm{a}$ & $70,32 \mathrm{a}$ & $57,35 \mathrm{~b}$ & $61,34 \mathrm{a}$ & ns & ns & 7,59 \\
\hline FDN $(N D F)$ & $47,16 a$ & $42,00 \mathrm{a}$ & $32,20 \mathrm{~b}$ & $40,79 a$ & ns & ns & 8,44 \\
\hline Amido (Starch) & $99,05 \mathrm{a}$ & $99,18 \mathrm{a}$ & $98,96 \mathrm{a}$ & $98,43 \mathrm{a}$ & $\mathrm{ns}$ & $\mathrm{ns}$ & 0,56 \\
\hline
\end{tabular}

${ }_{1} \mathrm{I}$ = efeitos principais entre os tipos de grãos de sorgo: BT vs AT $(P>0,05)$ e II = efeitos principais entre os métodos de conservação: seco vs ensilado ( $\left.>0,05\right)$. ns = não-significativo; Médias com letras diferentes na mesma linha diferem $(P<0,05)$ entre si pelo teste Tukey.

${ }^{1} I=$ main effects between the types of sorghum grains: $L T$ vs $H T(P>0.05)$ and $I I=$ main effects between the conservation methods: dry vs ensiled $(P>0.05)$

$n s=$ not significant ${ }^{b}$ Means with different letters within a row differ $(P<0.05)$ by Tukey test.

resultados diferentes em grande parte das pesquisas com outras espécies animais (Aguirre, 1984; Crenshaw et al., 1984; Hibberd et al., 1985; Defoor et al., 2001).

Poucas pesquisas avaliaram a capacidade de digestão do amido na espécie eqüina, entretanto, Gobesso (2001), utilizando-se cavalos fistulados no íleo, determinou o CDaAmido do trato digestivo total da dieta contendo grãos de sorgo, em que o valor de $98,3 \%$ foi similar ao encontrado neste trabalho. Adicionalmente, Santos et al. (2002) também encontraram similaridade entre os CDaAmido nas rações contendo grãos secos de milho ou SGUM na alimentação de potros. Contudo, a maioria das pesquisas relata a ocorrência do efeito benéfico do uso de grãos ensilados de sorgo sobre a digestibilidade do amido em animais ruminantes (Hibberd et al., 1985; Stock et al., 1987; Defoor et al., 2001). Rooney \& Pflugfelder (1986) ressaltaram que os grãos ensilados melhoram a capacidade de digestão do amido, por promoverem intensa hidrólise da matriz protéica do endosperma.

$O$ coeficiente de digestibilidade aparente da FDN $(32,20 \%)$ foi menor $(\mathrm{P}<0,05)$ na dieta contendo grãos secos de sorgo de alto teor de tanino em comparação às dietas constituídas por grãos de sorgo de baixo conteúdo de tanino ( secos ou ensilados) e por grãos ensilados de sorgo de alto nível de tanino. Estes valores foram inferiores aos CDaFDN obtidos por Gobesso (2001), em eqüinos que receberam dieta contendo grãos de sorgo como principal grão energético (63,64\% de FDN), e por Santos et al. (2002), avaliando dieta com $30 \%$ de inclusão da SGUM $(41,86 \%$ de FDN), de 55,82 e 57,52\%, respectivamente. O baixo valor do CDaFDN observado nesta pesquisa indica novamente o efeito negativo da qualidade do volumoso utilizado, que, por sua vez, comprometeu a digestibilidade de MS, devido ao elevado teor de FDN. Este efeito pode ter impedido o 
aparecimento esperado de diferenças significativas entre os CDaMS das fontes avaliadas, como ocorreu nos resultados dos CDaPB e CDaFDN.

Campos et al. (2001) relataram que a presença de taninos nas silagens de sorgo não influenciou $(\mathrm{P}>0,05)$ a degradação da FDN, em ruminantes. Em contraposição, neste trabalho, identificou-se que a dieta contendo maior teor de tanino, oriunda de grãos secos de sorgo de alto teor de tanino, interferiu negativamente $(\mathrm{P}<0,05)$ na digestibilidade da FDN em eqüinos. Este resultado sugere a influência negativa da presença de tanino nos concentrados sobre a população microbiana no intestino grosso de cavalos.

Verifica-se que os dados visualizados na Figura 1 não exibiram claramente uma distribuição exponencial, comprovada pela suave dominância do segmento decrescente da curva de excreção do marcador. Segundo Pond et al. (1988), este é um dos principais fatores na tomada de decisão entre a utilização dos modelos constituídos por um ou dois compartimentos de mistura e o interesse específico do trânsito das partículas em determinado segmento do trato digestivo do animal.

Após transformação logarítmica (ln) destas curvas de excreção, foram obtidos os parâmetros do trânsito gastrintestinal para fase sólida da digesta das dietas experimentais (Tabela 6). Não foram detectadas diferenças significativas $(\mathrm{P}>0,05)$ para os parâmetros analisados, observando-se valores médios de $5,98 \% / \mathrm{h}, 16,54 \% / \mathrm{h}, 28,42 \mathrm{~h}$ e 51,03h, respectivamente, para k1, k2, TT e TMRT.

Há poucos trabalhos publicados sobre o uso de diferentes marcadores, dietas e modelos comportamentais, avaliando os parâmetros do trânsito gastrintestinal, em eqüinos. Contudo, este tema tem sido bastante pesquisado na área de ruminantes, com a utilização de modelos constituídos por dois compartimentos, observando-se similaridade nas observações destes parâmetros entre eqüinos e bovinos, de acordo com Uden et al. (1982)

Nos estudos com ruminantes, a taxa de passagem das partículas mais lentas, ou seja, o fluxo pelo rúmen $(\mathrm{k} 1)$ em alimentação exclusiva de volumoso ou uma mistura de concentrado e volumoso apresentou valores médios de $2 \mathrm{e}$ 5\%/h, respectivamente (Vega \& Poppi, 1997; Vega et al., 1998; Ezequiel et al., 2003; Soares et al., 2003). No cavalo, o compartimento com característica de fluxo lento de partículas é o intestino grosso; nesta pesquisa, foi obtido valor médio de $5,98 \% / \mathrm{h}$ para $\mathrm{k} 1$, estando adequado para animais que consumiram $50 \%$ de concentrado e $50 \%$ de volumoso.

Com relação ao fluxo de partículas rápidas (k2), referindo-se ao intestino grosso nos bovinos e estômago nos eqüinos, neste trabalho, o resultado médio foi de $16,5 \%$, similar aos valores observados em ruminantes recebendo dieta mista, que variaram de 17 a 21\%/h (Vega \& Poppi, 1997; Soares et al., 2001; Bueno, 2002; Ezequiel et al., 2003).

Para eqüinos, o TT com valor médio de $28,42 \mathrm{~h}$ expressa o tempo gasto para a partícula percorrer o intestino delgado, o qual se assemelha ao valor registrado por Oliveira et al. (2003), de 25,5 h, em eqüinos consumindo ração com $60 \%$ de volumoso e $40 \%$ de concentrado, e supera o obtido por Holland et al. (1998), de 18,1h, para a mesma espécie animal alimentando-se de dieta mista. Adicionalmente, este parâmetro superou os resultados de 12,26a 23, 0h encontrados nos estudos com ruminantes consumindo concentrado e volumoso. De forma contrária, o TMRT, que compreende o tempo necessário para a partícula atravessar todo o trato digestivo, foi inferior nos eqüinos, de 52,91h (obtido neste ensaio) versus 58 a $64 \mathrm{~h}$, em experimentos com bovinos alimentados com dietas mistas (Krysl et al., 1988; Ezequiel et al., 2003). Os parâmetros do trânsito gastrintestinal avaliados em eqüinos, utilizando-se o modelo comportamental constituído por dois compartimentos (Grovum \& Williams, 1973), quando comparado aos resultados verificados em ruminantes, foram satisfatórios e coerentes considerando-se as particularidades anátomo-fisiológicas digestivas distintas entre as espécies.

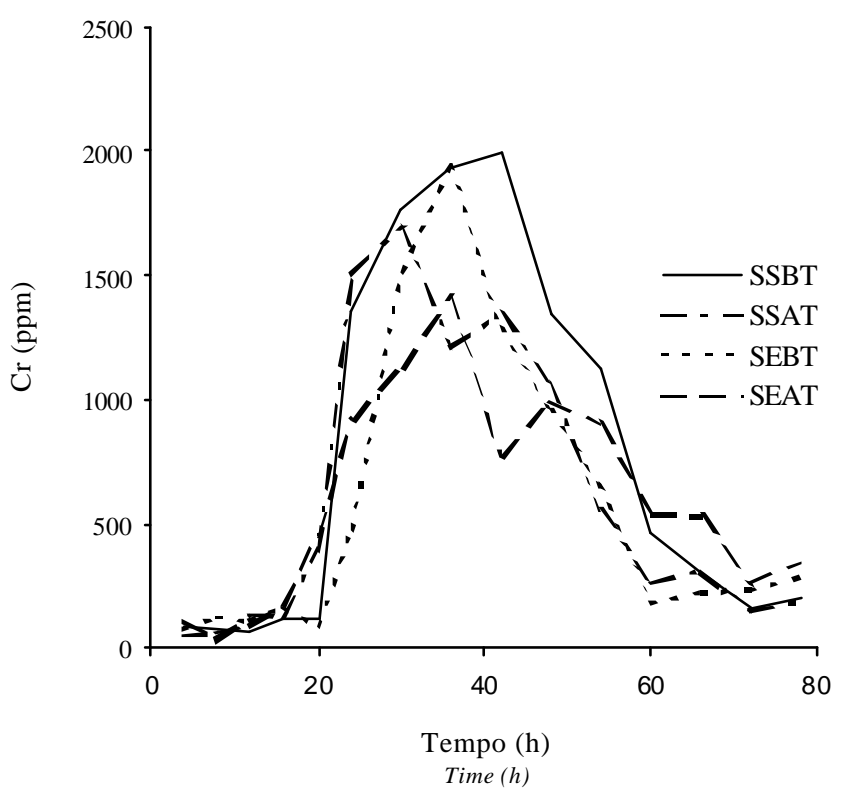

Figura 1 - Perfil de excreção do Cr nas fezes de eqüinos alimentados com dietas contendo grãos secos de sorgo de baixo (SSBT) e alto conteúdos de tanino (SSAT) e grãos úmidos de sorgo de baixo (SEBT) e alto conteúdos de tanino (SEAT).

Figure 1 - Profile of excretion of $\mathrm{Cr}$ in the equines faeces fed diets containing dry sorghum grains of low tannin (DSLT), dry sorghum grains of high tannin (DSHT), ensiled sorghum grains of low tannin (ESLT) and, ensiled sorghum grains of high tannin (ESHT). 
Tabela 6 - Taxa de passagem no intestino grosso (k1), taxa de passagem no estômago (k2), tempo de trânsito (TT) e tempo médio de retenção total (TMRT) da fase sólida da digesta em eqüinos alimentados com dietas contendo grãos de sorgo com baixo e alto teores de tanino sob dois métodos de conservação

Table 6 - Passage rate in large intestine ( $k 1)$, passage rate in stomach ( $k 2)$, transit time $(T T)$ and total mean retention time (TMRT) of the solid phase of digesta in equines fed diets containing sorghum grains with low and high tannin submitted to two methods of conservation

\begin{tabular}{|c|c|c|c|c|c|c|}
\hline \multirow[t]{3}{*}{$\begin{array}{l}\text { Parâmetro } \\
\text { Parameter }\end{array}$} & \multicolumn{4}{|c|}{$\begin{array}{l}\text { Dieta contendo grãos de sorgo } \\
\text { Diet containing sorghum grain }\end{array}$} & \multirow[t]{3}{*}{$\begin{array}{c}\text { Média } \\
\text { Mean }\end{array}$} & \multirow[t]{3}{*}{$\mathrm{CV}(\%)$} \\
\hline & \multicolumn{2}{|c|}{$\begin{array}{l}\text { Baixo tanino } \\
\text { Low tannin }\end{array}$} & \multicolumn{2}{|c|}{$\begin{array}{l}\text { Alto tanino } \\
\text { High tannin }\end{array}$} & & \\
\hline & $\begin{array}{c}\text { Seco } \\
\text { Dry }\end{array}$ & $\begin{array}{c}\text { Ensilado } \\
\text { Ensiled }\end{array}$ & $\begin{array}{c}\text { Seco } \\
\text { Dry }\end{array}$ & $\begin{array}{c}\text { Ensilado } \\
\text { Ensiled }\end{array}$ & & \\
\hline $\mathrm{k} 1(\% / \mathrm{h})$ & 6,00 & 6,28 & 6,30 & 5,35 & 5,98 & 14,23 \\
\hline k2 (\%/h) & 14,19 & 16,06 & 19,47 & 16,42 & 16,54 & 20,24 \\
\hline $\mathrm{TT}(\mathrm{h})$ & 25,94 & 33,46 & 26,35 & 27,91 & 28,42 & 76,86 \\
\hline TMRT (h) & 52,24 & 56,23 & 47,90 & 55,28 & 52,91 & 48,73 \\
\hline
\end{tabular}

${ }_{1}^{1}$ Médias não diferem $(P>0,05$ pelo teste Tukey.

${ }^{1}$ Means did not differ $(P>0.05)$ by Tukey test.

Tabela 7 - Taxa de recuperação do marcador (\%) e tempo médio de retenção (TMR) em eqüinos alimentados com dietas contendo grãos de sorgo de baixo e alto teores de tanino sob dois métodos de conservação

Table 7 - Rate of recuperation of the marker (\%) and mean retention time (MRT) in equines fed diets containing sorghum grains with low and high tannin submitted to two methods of conservation

\begin{tabular}{|c|c|c|c|c|c|c|c|}
\hline \multirow[t]{3}{*}{ Item } & \multicolumn{4}{|c|}{$\begin{array}{l}\text { Dieta contendo grãos de sorgo } \\
\text { Diet containing sorghum grain }\end{array}$} & \multicolumn{2}{|c|}{$\begin{array}{l}\text { Efeito principal }{ }^{1} \\
\text { Main effect }\end{array}$} & \multirow[t]{3}{*}{$\mathrm{CV}(\%)$} \\
\hline & \multicolumn{2}{|c|}{$\begin{array}{l}\text { Baixo tanino } \\
\text { Low tannin }\end{array}$} & \multicolumn{2}{|c|}{$\begin{array}{l}\text { Alto tanino } \\
\text { High tannin }\end{array}$} & \multirow[t]{2}{*}{ I } & \multirow[t]{2}{*}{ II } & \\
\hline & $\begin{array}{l}\text { Seco } \\
\text { Dry }\end{array}$ & $\begin{array}{c}\text { Ensilado } \\
\text { Ensiled }\end{array}$ & $\begin{array}{l}\text { Seco } \\
\text { Dry }\end{array}$ & $\begin{array}{r}\text { Ensilado } \\
\text { Ensiled }\end{array}$ & & & \\
\hline$\%$ Recup. & 99,22 & 106,57 & 105,35 & 101,14 & $\mathrm{~ns}$ & $\mathrm{~ns}$ & 26,50 \\
\hline TMR $(h)^{2}$ & 26,12 & 22,87 & 21,55 & 27,37 & $\mathrm{~ns}$ & $\mathrm{~ns}$ & 24,48 \\
\hline TMR $(h)^{3}$ & 37,77 & 41,15 & 38,02 & 40,45 & ns & $*$ & 5,18 \\
\hline
\end{tabular}

${ }_{1} \mathrm{I}$ = efeitos principais entre os tipos de grãos de sorgo: BT vs AT $(\mathrm{P}>0,05)$ e II = efeitos principais entre os métodos de conservação: seco vs ensilado.

2 Obtido, segundo Grovum \& Williams et al. (1973).

3 Obtido, segundo Blaxter et al. (1956).

ns = não-significativo; ${ }^{*}$ efeito significativo entre as médias para o método de conservação $(P<0,05)$; médias entre tratamentos não diferem $(P>0,05)$ pelo teste Tukey.

${ }_{1} I=$ main effects between the types of sorghum grains: $L T$ vs $H T(P>0.05)$ and II = main effects between the conservation methods: dry vs ensiled.

2 Value obtained, as Grovum \& Williams et al. (1973).

${ }^{3}$ Value obtained, as Blaxter et al. (1956).

$n s=$ not significant; ${ }^{*}$ significant effect between means for the conservation methods $(P<0.05)$; means among treatments did not differ $(P>0.05)$ by Tukey test.

A taxa de recuperação do marcador apresentou valor médio de recuperação de $103,7 \%$, não havendo diferença significativa entre os tipos de sorgo testados, demonstrando ser adequada a quantidade de $30 \mathrm{~g} \mathrm{Cr}$-FDN oferecida aos eqüinos, em dose única (Tabela 7). Assim, a técnica analítica nuclear foi empregada com sucesso para determinar o marcador nas fezes de cavalos, revelando-se uma técnica promissora na experimentação com eqüinos.

Na tentativa de maior avaliação do trânsito gastrintestinal em eqüinos, obtendo-se parâmetro comparativo entre as pesquisas realizadas com esta espécie animal, calculou-se o TMR das dietas experimentais segundo o modelo proposto por Blaxter et al. (1956) (Tabela 7). Como esta modelagem considera a existência de dois compartimentos de mistura no próprio estômago dos ruminantes (rúmen e abomaso), quando adaptada nos eqüinos, este modelo possui a capacidade de avaliar apenas um compartimento de mistura. Conseqüentemente, baseando-se nestas considerações, a maioria dos trabalhos com eqüinos mensura apenas um parâmetro de trânsito, o TMR.

A partir da análise dos TMR obtidos pela modelagem de Blaxter et al. (1956), verificou-se efeito significativo $(\mathrm{P}<0,05)$ do método de conservação dos grãos de sorgo ( $\operatorname{cecos}$ vs ensilados). Desta forma, as dietas contendo silagens de grãos úmidos de sorgo resultaram em maior TMR da digesta no trato digestivo, de 40,08h, enquanto as dietas contendo grãos secos de sorgo, de 37,9h. Entre tanto, este maior tempo de retenção observado nas dietas contendo silagens de grãos úmidos de sorgo não resultou em melhor capacidade digestiva dos nutrientes 
em compara ção às éguas que consumiram grãos secos de sorgo em seu concentrado.

Cuddeford et al. (1995), analisando o tempo de trânsito gastrintestinal de eqüinos, verificaram que o TMR da dieta com alto teor de fibra $(62,1 \% \mathrm{FDN})$, de $38,4 \mathrm{~h}$, foi significativamente inferior que as de menor teor de fibra $(40,1 \%$ FDN), de 51,9h, similarmente aos resultados obtidos por Pagan et al. (1998), em que o maior TMR, de 41,6h, foi observado em eqüinos consumindo dieta mista em comparação aos cavalos recebendo somente volumoso. Pearson \& Merrit (1991) observaram que o TMR para cavalos alimentados com palhada superou o grupo que consumiu feno, sendo os valores de 34,8 e 29,9h, respectivamente. Oliveira et al. (2001) não encontraram diferenças $(P>0,05)$ para o TMR entre as dietas compostas por diferentes proporções de volumoso:concentrado, de 100:0, 80:20, 60:40 e 40:60, na alimentação de eqüinos, com valores médios de 42,3; 40,2; 42,3 e 45,7h, respectivamente.

A literatura evidencia que os resultados da avaliação do trânsito gastrintestinal na experimentação de eqüinos são muito divergentes quanto ao efeito do conteúdo da FDN na dieta sobre o TMR da fase sólida da digesta. Contudo, o valor médio para TMR obtido neste trabalho, de 39,35h, segundo recomendações de Blaxter et al. (1956), foi similar aos observados na literatura consultada (Pearson \& Merrit, 1991; Cuddeford et al., 1995; Pagan et al., 1998; Oliveira et al., 2001) e superiores aos verificados com a metodologia de Grovum \& Williams (1973), em que o valor médio foi de $24,48 \mathrm{~h}$, não se encontrando uma explicação para este fato.

Vale ressaltar que o TMR quantificado segundo o método de Grovum \& Williams (1973), nesta pesquisa, não sofreu alteração $(\mathrm{P}>0,05)$ das fontes de variação estudadas (tipo de grão e/ou método de conservação), diferentemente do encontrado pelo modelo de Blaxter et al. (1956) (Tabela 7). Esta diferença entre as modelagens utilizadas pode ser explicada, parcialmente, pela discrepância entre os coeficientes de variação envolvidos, sendo de $24,48 \%$ para o modelo de Grovum \& Williams (1973) e de somente 5,18\% para o método de Blaxter et al. (1956).

De acordo com Pond et al. (1988) para a tomada de decisão entre os modelos disponíveis para mensurar o trânsito gastrintestinal nos animais de produção, além da presença de uma curva de excreção com distribuição exponencial e do interesse específico do fluxo da ingesta em determinado segmento do trato digestivo, deve-se considerar também o coeficiente de variação oferecido pelo modelo. Neste trabalho, esta escolha poderia recair sobre o modelo de Blaxter et al. (1956), em razão da ausência de uma curva característica de excreção e do menor coeficiente de variação apresentado, melhorando a acurácia do parâmetro mensurado (TMR). Todavia, este modelo não permite avaliar em eqüinos outras variáveis sobre o funcionamento do sistema digestivo desta espécie animal. Portanto, cabe ao pesquisador ponderar sobre os benefícios e as limitações dos modelos em relação aos seus objetivos, considerando-se as características do alimento a ser testado e as particularidades digestivas da unidade experimental utilizada.

\section{Conclusões}

Apesar de a forma de conservação dos grãos de sorgo não interferir na aceitabilidade e no consumo das rações para eqüinos, o híbrido com alto teor de tanino deve ser ensilado para não afetar adversamente a digestibilidade da proteína e da fibra.

A inclusão de grãos ensilados de sorgo na alimentação de eqüinos promove trânsito mais lento da digesta pelo trato gastrintestinal.

O modelo de Blaxter et al. (1956) é o mais adequado, quando não houver interesse específico em determinado segmento do trato digestivo e, principalmente, se ocorrer limitação na qualidade dos dados coletados, por diminuir a variabilidade experimental, tornando-se preciso na avaliação do trânsito gastrintestinal de eqüinos.

\section{Literatura Citada}

AGUIRRE, E.E. Effects of moisture level of fermented corn and corn grain processing of digestion in beef animals fed high concentrate diets. Journal of Animal Science, v.59, n.51, p.443, 1984.

ARAÚJO, K.V. Métodos para determinação da digestibilidade aparente dos nutrientes em eqüinos. Lavras: Universidade Federal de Lavras, 1999. 155p. Tese (Doutorado em Zootecnia) Universidade Federal de Lavras, 1999.

BLAXTER, K.L.; GRAHAM, N.Mc.; WAINMAN, F.W. Some observations on the digestibility of food sheep, and on related problems. British Journal of Nutrition, v.10, p.69-91, 1956.

BUENO, I.C.S. Cinética digestiva e síntese microbiana ruminal em ovinos alimentados com fenos de três qualidades distintas. Piracicaba: Escola Superior de Agricultura Luiz de Queiroz, 2002.89p. Tese (Doutorado em Ciência Animal) - Escola Superior de Agricultura Luiz de Queiro, 2002.

CAMPOS, W.E.; SATURNINO, H.M.; SOUSA, B.M. et al. Avaliação da degradabilidade "in situ" da fibra detergente neutro e fibra em detergente ácido de quatro genótipos de sorgo com diferentes teores de tanino. In: REUNIÃO ANUAL DA SOCIEDADE DE ZOOTECnIA, 38., 2001, Piracicaba. Anais... Piracicaba: Sociedade Brasileira de Zootecnia, 2001. (CD-ROM).

COCHRAN, W.G.; COX, G.M. Experimental design. New York: John Wiley and Sons, 1967. 617p.

COUSINS, B.W.; TANKSLEY, T.D.; KNABE, D.A. et al. Nutrient digestibility and performance of pigs fed sorghums varying in tannin concentration. Journal of Animal Science, v.53, n.6, p.1524-1537, 1981. 
CRENSHAW, J.D.; PEO, E.R.; LEWIS, A.J. et al. The nutritional value of high moisture and reconstituted sorghum grain for swine. Journal of Animal Science, v.58, n.5, p.1222-1230, 1984.

CUDDEFORD, D.; WOODHEAD, A.; MUIRHEAD, R.H. A comparison between the nutritive value of short-cutting cycle, high temperature-dried alfalfa and timothy hay for horses. Equine Veterinary Journal, v.24, p.84-89, 1992.

CUDDEFORD, D.; PEARSON, R.A.; ARCHIBALD, R.F. et al Digestibility and gastro-intestinal transit time of diets containing different proportions of alfalfa and oats straw given to Thoroughbreds, Shetland ponies, Highland ponies and donkeys. Animal Science, v.61, p.407-417, 1995.

DEFOOR, P.J.; COLE, N.A.; GALYEAN, M.L. et al. Effects of grain sorghum planting and processing method on nutrient digestibility and retention by ruminants. Journal of Animal Science, v.79, p.19-25, 2001.

EZEQUIEL, J.M.B.; QUEIROZ, M.A.A.; MENDES, A.R. et al. Taxa de passagem, consumo e digestibilidade da fibra da cana de açúcar"in natura" ou hidrolisada em bovinos. In: REUNIÃO ANUAL DA SOCIEDADE BRASILEIRA DE ZOOTECNIA, 40. 2003, Santa Maria. Anais... Santa Maria: Sociedade Brasileira de Zootecnia/Gmosis, 2003. (CD-ROM).

GIBBS, P.G.; POTTER, G.D.; SCHELLING, G.T. et al. The significance of small vs large intestinal digestion of cereal grain and oilseed protein in the equine. Journal of Equine Veterinary Science, v.16, n.2, p.60-65, 1996

GOBESSO, A.A.O. Digestão pré-cecal e total de nutrientes utilizando dietas para eqüinos fistulados no íleo. Jaboticabal: Universidade Estadual Paulista, 2001. 89p. Tese (Doutorado em Nutrição Animal) - Universidade Estadual Paulista, 2001.

GRIGOLETTO, L.C.; FURLAN, A.C.; MURAKAMI, A.E. et al. Valor nutritivo das silagens de grãos úmidos de sorgo de alto ou de baixo conteúdo de taninos para frangos de corte. In REUNIÃO ANUAL DA SOCIEDADE BRASILEIRA DE ZOOTECNIA, 40., 2003, Santa Maria. Anais... Santa Maria: Sociedade Brasileira de Zootecnia/Gmosis, 2003. (CD-ROM).

GROVUM, W.L.; WILLIAMS, V.J. Rate of passage of digesta in sheep. 4. Passage of marker through the alimentary tract and the biological relevance of rate constants derived from the changes in concentration of marker in faeces. British Journal of Nutrition, v.30, p.313-329, 1973.

HAENLEIN, G.F.; SMITH, R.C.; YOON, Y.M. Determination of the faecal excretion rate of horses with chromic oxide. Journal of Animal Science, v.25, n.4, p.1091-1095, 1966.

HIBBERD, C.A.; WAGNER, D.G.; HINTZ, R.L. et al. Effect of sorghum grain variety and reconstitution on site and extent of starch and protein digestion in steers. Journal of Animal Science, v. 61, n.3, p.702-712, 1985.

HINTZ, H.F.; LOY, R.G. Effects of pelleting on the nutritive value of horses rations. Journal of Animal Science, v.25, n.4, p.1059-1062, 1966.

HOLLAND, J.L.; KRONFELD, D.S.; SKLAND, D. et al. Calculation of fecal kinetics in horses fed hay or hay and concentrate. Journal of Animal Science, v.76, p.1937-1944, 1998.

KRYSL, L.J.; GALYEAN, M.L.; ESTELL, R.E. et al. Estimating digestibility and faecal output in lambs using internal and external markers. Journal of Agriculture Science, v.111, p.19-25, 1988.

LEWIS, L.D. Nutrição clínica eqüina: alimentação e cuidados. São Paulo: Roca, 2000. 710p.

MACRAE, J.C.; ARMSTRONG, D.G. Enzyme method for determination of linked glucose polymers in biological materials. Journal of Science Agriculture, v. 19, p.578-581, 1968.

MAKKAR, H.P.S. Chemical, protein precipitation and bioassays for tannins, effects and fate of tannins, and strategies to overcome detrimental effects of feeding tannin-rich feeds. In:
SEMINAR OF THE FAO-CIHEAM SUB-NETWORK ON SHEEP AND GOAT NUTRITION, 9., 2001, Hammamet, Tunisia. Proceedings... Vienna: FAO/IAEA, 2001. (CD-ROM).

MAKKAR, H.P.S.; DAWRA, R.K.; SINGH, B. Determination of both tannin and protein in a tannin-protein complex.Journal of Agriculture Food Chemistry, v.36, p.523-525, 1988

MITARU, B.N.; REICHERT, R.D.; BLAIR, R. Improvement of the nutritive value of high tannin sorghums for broiler chickens by high moisture storage (reconstitution).Poultry Science, v.62, n.10, p.2065-2072, 1983

MYER, R.O.; GORBET, D.W.; COMBS, G.E. Nutritive value of high and low-tannin grain sorghums harvested and stored in the high-moisture state for growing-finishing swine. Journal of Animal Science, v.62, p.1290-1297, 1986.

NASCIMENTO FILHO, V.F. Técnicas analíticas nucleares de fluorescência de raios $X$ por dispersão de energia (EDXRF) e por reflexão total (TXRF). Piracicaba: Escola Superior de Agricultura Luiz de Queiroz, 1999. 32p.

NATIONAL RESEARCH COUNCIL - NRC. Nutrient requirements of horses. 5.rev.ed. Washington: National Academy of Sciences, 1989. 100p.

OLIVEIRA, C.A.A.; ALMEIDA, F.Q.; CORASSA, A. et al. Cinética da passagem da digesta e balanço hídrico em eqüinos alimentados com diferentes níveis de fibra. In: REUNIÃO ANUAL DA SOCIEDADE BRASILEIRA DE ZOOTECNIA, 38., 2001, Piracicaba. Anais... Piracicaba: Sociedade Brasileira de Zootecnia, 2001. (CD-ROM).

OLIVEIRA, C.A.A.; ALMEIDA, F.Q.; VALADARES FILHO, S.C. et al. Estimativa da digestibilidade aparente de nutrientes em dietas para eqüinos, com o uso de óxido crômico e indicadores internos. Revista Brasileira de Zootecnia, v.32, n.6, p.16811689, 2003 (supl. 1).

PAGAN, J.D.; HARRIS, P.A.; BREWSTER-BARNES, T. et al. Exercise affects digestibility and rate of passage of all-forage and mixed diets in thoroughbreds horses. Journal of Nutrition, v.128, p.2704S-2707S, 1998.

PATRICIO, V.M.I.; FURLAN, A.C.; MOREIRA, I. et al. Valor nutritivo das silagens de grãos úmidos de sorgo de alto ou de baixo conteúdo de taninos para leitões em fase de creche. In: REUNIÃO ANUAL DA SOCIEDADE BRASILEIRA DE ZOOTECNIA, 40., 2003, Santa Maria, Anais... Santa Maria: Sociedade Brasileira de Zootecnia/Gmosis, 2003. (CD-ROM).

PEARSON, R.A.; MERRIT, J.B. Intake, digestion and gastrointestinal transit time in resting donkeys and ponies and exercised donkeys given ad libitum hay and straw diets. Equine Veterinary Journal, v.23, n.5, p.339-343, 1991.

POND, K.R.; ELLIS, W.C.; MATIS, J.H. et al. Compartment models for estimating attributes of digesta flow in cattle. British Journal of Nutrition, v.60, p.571-595, 1988.

ROONEY, L.W.; PFLUGFELDER, R.L. Factors affecting starch digestibility with special emphasis on sorghum and corn. Journal of Animal Science, v.63, n.3, p.1607-1623, 1986.

SAINT JUST, C.A. Digestibilidade de nutrientes em rações contendo milho e sorgo em éguas gestantes. Piracicaba: Escola Superior de Agricultura Luiz de Queiroz, 1989. 56p. Dissertação (Mestrado em Ciência Animal) - Escola Superior de Agricultura Luiz de Queiroz, 1989.

SANTOS, C.P.; FURTADO, C.E.; JOBIM, C.C. et al. Avaliação da silagem de grãos úmidos de milho na alimentação de eqüinos em crescimento: valor nutricional e desempenho. Revista Brasileira de Zootecnia, v.31, n.3, p.1214-1222, 2002.

STATISTICAL ANALYSIS SYSTEM - SAS. SAS user's: guide: statistics. Cary: 2000. $211 \mathrm{p}$

SILVA, D.J. Análise de alimentos (métodos químicos e biológicos). Viçosa, MG: Universidade Federal de Viçosa, 1989. 166p.

SOARES, J.P.G.; AROEIRA, L.J.M.; VERNEQUE, R.S. et al. Estimativas de consumo e da taxa de passagem do capim-elefante (Pennisetum purpureum Schum.) sob pastejo de vacas em lactação. Revista Brasileira de Zootecnia, v.30, n.6, p.2183-2191, 2001 (supl.). 
SOARES, J.P.G.; DERESZ, F.; AROEIRA, L.J.M. et al. Efeito da suplementação de concentrado sobre o consumo, conteúdo ruminal, taxa de passagem pelo trato gastrintestinal e parâmetros ruminais de vacas mestiças recebendo capim elefante picado. In: REUNIÃO ANUAL DA SOCIEDADE BRASILEIRA DE ZOOTECNIA, 40., 2003, Santa Maria, Anais... Santa Maria: Sociedade Brasileira de Zootecnia/Gmosis, 2003. (CD-ROM).

SOLOGUREN L.J. Commodites - O caro do milho. Alimentação Animal, n.2, p.10-11, 2000

STOCK, R.A.; BRINK, D.R.; KREIKEMEIER, K.K. et al. Evaluation of early-harvested and reconstituted grain sorghum in finishing steers. Journal of Animal Science, v.65, p.548556, 1987.

STREETER, M.N.; WAGNER, D.G.; HIBBERD, C.A. et al. The effect of sorghum grain variety on site and extent of digestion in beef heifers. Journal of Animal Science, v.68, p.1121$1132,1990$.

UDEN, P.; COLUCCI, P.E.; Van SOEST, P.J. Investigation of chromium, cerium and cobalt as markers in digesta. Rate of passage studies. Journal of the Science of Food and Agriculture, v.31, p.625-632, 1980.

UDEN, P.; ROUNSAVILLE, T.R.; WIGGANS, G.R. et al. The measurement of liquid and solid digesta retention in ruminants, equines and rabbits given Timothy hay. British Journal of Nutrition, v.48, p.329-339, 1982.
VANDER NOOT, G.W.; SYMONS, L.D.; JYDMAN, R.K. Rate of passage of various feedstuffs through the digestive tract of horses. Journal of Animal Science, v.26, n.6, p.1309-1311, 1967.

Van KEULEN, J.; YOUNG, B.A. Evaluation of acid insoluble ash as a natural marker for digestibility studies. Journal of Animal Science, v.44, n.2, p.282-287, 1977.

VEGA, A.; POPPI, D.P. Extent of digestion and rumen condition as factor affecting passage of liquid and digesta particles in sheep. Journal of Agriculture Science, v.128, p.207-215, 1997.

VEGA, A.; GASA, J.; CASTRILLO, C. et al. Passage through the rumen and large intestine of sheep estimated from faecal marker excretion curves and slaughter trials. British Journal of Nutrition, v.80, p.381-389, 1998.

WHITAKER, H.M.; CARVALHO, R.L. Substituição do milho pelo sorgo em rações para eqüinos. Revista Brasileira de Zootecnia, v.26, n.1, p.139-143, 1997.
Recebido: 12/11/2004 Aprovado: $5 / 6 / 2007$ 